\title{
Nach-Bilder: Mozart 2006
}

Enrico Danieli

Korrespondenz:

Dr. med. Enrico Danieli

Via dei Colli 22

CH-6648 Minusio
Dass in Mozarts Geburtshaus in der Getreidegasse 9 in Salzburg, dass in Mozarts Geburtszimmer - blendendweisse Wände, ein leuchtendweisser Himmel - zwölf Blaugänse keilförmig zum hellen - ostseitigen? - Lichtfenster fliegen, dass hier (installiert von Robert Wilson, Opernregisseur) Bewegtheit, Wachsamkeit am Anfang von Mozarts Werk steht, dass der Vogelflug Fliegen, Schweben und Beflügelung versinnbildlicht, dass Meeresrauschen und Möwenschreie die Leerstelle Geburt akustisch begreifbar machen, dass hier in diesem Zimmer Gänse wie Seelen ihre Flügel ausspannen: Diese Wahrnehmung begleitet uns durch die Ausstellung und weiter, weiter: als ob schliesslich die Helligkeit des leeren Raums als Nach-Bild Besitz von uns ergriffen hätte.

Der umständlich vom Auge zu verfolgende Vogelzug diente einst Deutern zu Voraussagen zukünftiger - meist politischer - Ereignisse. Heute, im neuen Zeitalter alter Seuchen, sind wissenschaftliche Auguren gefragt, die die Routen der Zugvögel beobachten, um Schlüsse zu ziehen über Ausbreitungswege neuer Pandemien. Unsere Augen richten sich nach Südosten, Einflugs- und Zugkorridorkontrollen würden helfen, Gefahren abzuschätzen, von Belang seien aber nur unsere Wintergäste: Stock-, Tafel- und Reiherenten, Lachmöwen, Wildgänse. «Du brauchst dich nicht zu fürchten, Nils, solange ich bei dir bin.» Der Knabe Nils, zum Däumling geworden, wird vom Gänserich Martin nach Lappland mitgenommen; Bären, Wölfe, Adler sind Freund oder Feind. Als Nils von so vielen Feinden hört, die ihm mit dem Tod drohen, gibt er alle Hoffnung auf ein langes Leben auf, er hat keine besondere Angst vor dem Tod. Denn vielleicht ist es die Vogelperspektive, die das Grosse klein und uns angstlos macht. «Da der Tod, genau zu nemmen, der wahre Endzweck unseres Lebens ist», heisst es im Brief Mozarts an seinen auf den Tod kranken Vater vom 4. April 1787, und dass er sich keinen Tag zu Bette lege, ohne zu bedenken, dass er vielleicht den anderen Tag nicht mehr sein werde: «So habe ich mich mit diesem wahren besten Freund des Menschen so bekannt gemacht, dass sein Bild allein nichts Schreckendes mehr für mich hat ...» In Salzburg an diesem Samstag, dem 11. November 2006, fette Martinigänse werden aufgetischt, der Himmel ist von einer hellen, durchsichtigen Bläue, werde ich an periphere, zentrale und diffuse Verfettung erinnert, an Sudanfärbung, an das Präparat: «Leber Gans» im Mikroskop, an den Paraffinschnitt mit herausgelöstem Fett, und es ist, als ob die nun derart entstandene (optische) Leere sich hier an diesem Ort allmählich (akustisch) füllen würde. Und Konrad Lorenz, auf Umwegen über Raben, die hoch über der Stadt kreisen, führt mich weiter zurück zu den Grau- (nicht Blau-)Gänsen, zum «sogenannt Bösen», zu den «Todsünden der Menschheit»: Hier scheinen überzeugende Erklärungen für menschliches Sosein gefunden worden zu sein aus dem Bereich der Verhaltensforschung. Der Nobelpreisträger, Bindeglied zwischen Medizin, Biologie und Physiologie, gilt als Erklärungsvermittler des Bösen, doch nur so lange, bis von erwiesenen Zusammenhängen nationalsozialistischer Ideologien mit den vom Forscher vorausgelieferten Theorien über Rassenhygiene die Rede ist: Myriaden von (weissen) Gänsen über dem Vernichtungslager Sobibor. Hier werden von den Nazis zu Hunderten Gänse gehalten, denn Schnattern und Kreischen übertönen die Schreie der in den Tod in den Gaskammern getriebenen Menschen, die, die als nächste an die Reihe kommen, sollen bis zuletzt Gänse und nicht Menschen schreien hören. Und dass Gänse tot vom schwarzen Himmel fallen, ermattet und ausgezehrt von den Vogelgrippeviren, weckt wieder Erinnerungen an Nils Holgersson: «Nun genoss er den schnellen Flug durch die frische Luft, und ihm war, als flöge er seinem Kummer und allen Sorgen davon, er glaubte, den Himmel noch nie so tiefblau gesehen zu haben wie heute.» Wir kehren zurück in das blendende Weiss von Mozarts Geburtszimmer, wir hören aus anderen Räumen seine Musik, aus seinem schwarzen Arbeitszimmer seine Nozze, seine Susanna, seinen Figaro, seinen Cherubino, und wir sehen reliquienartig eingelassen in die schwebenden Wände die gemalten Noten von KV 1 von 1764, und wir sehen sein Elfenbeinrelief, seine Kinderviola, seine Brieftasche, seine Tabakdose, seine Haare, seine Berlocke, seinen Ring, seine Perlmuttknöpfe, und wir hören laut Meeresrauschen und Vögelkreischen.

Später am Tag im Tanzmeisterhaus folgen wir den Führungen durch sein Leben und Werk. Zum Schluss im schwarzen Filmvorführraum, wir sitzen auf Holzkuben, haben Mühe, in der Dunkelheit vom hellen, kegelförmig gebündelten Licht der Projektoren nicht geblendet zu werden, wird der 2. Satz der Haffner-Symphonie gespielt, und nun ist es tatsächlich so, dass hier mitten im Andante Sausen und Brausen rauschender Schwingen davonziehender Zugvögel im nun hellsten Himmel über Salzburg zu hören sind. 